\title{
LETTERS
}

\section{Recognizing subclinical hyposplenism}

Drs. Yoshimura and Yoon ${ }^{1}$ give a lucid description of the potentially lethal consequences of community-acquired infection in the setting of asplenia. However, they do not highlight measures to identify those individuals who have unrecognized, subclinical hyposplenism.

The peripheral blood film (smear) may yield helpful and potentially lifesaving clues. Even in stable, asymptomatic patients, there will be evidence of HowellJolly bodies, acanthocytes, target cells and unexplained thrombocytosis. ${ }^{2}$ The finding of these abnormalities should raise the suspicion of hyposplenism and, if confirmed, would trigger the appropriate prophylactic measures, ${ }^{1}$ such as patient and caregiver education, vaccination or early antibiotic use.

\section{Matthew D. Seftel MD MPH}

Hematologist, Section of Hematology/

Oncology, Department of Internal

Medicine, Max Rady College of Medicine, Winnipeg, Man.

- Cite as: CMAJ 2019 January 7;191:E21. doi: $10.1503 / \mathrm{cmaj} .70852$

\section{References}

1. Yoshimura S, Yoon H-S. Invasive pneumococcal infection in a man with hyposplenism. CMAJ 2018;190:E1084.

2. Mohamed M. Functional hyposplenism diagnosed by blood film examination. Blood. 2014;124:1997.

Competing interests: None declared. 